\section{MS23-05 The structure of hydrophobic hydration}

Janusz Lipkowski, Institute of Physical Chemistry, Polish Academy of Sciences, Kasprzaka 44/52, 01224 Warszawa, Poland;

E-mail: jlipkowski@ichf.edu.pl

Hydrophobic hydration is the concept derived in the 1950 s from thermodynamic studies from which it became clear that, in addition to hydrogen bonding, water has some extra ability to bind, without hydrophilic interactions, molecular species which are routinely considered hydrophobic. The outcome, e.g. in the form of stable compounds of water and hydrocarbons, is impressive. This binding is based upon structure effects, namely on aggregation of water molecules around a 'structure-directing agent' (as named by silica chemists) or 'template' (commonly used by organic synthetic chemists) or, simply, guest component. This is a typical collective phenomenon, not easily corresponding to the classical tools of chemists who prefer to rationalize interactions in terms of bonds between specified atoms. Hydrate solids are often non-stoichiometric, phenomenon which is certainly unknown in molecular chemistry while rather common in solid state sciences.

Hydrophobic hydration is a common phenomenon and is important from different viewpoints. Directly as a source of special type of material which may be of practical importance.Indirectly as a means of facilitating synthesis of organic and/or inorganic substances either in nature (as illustrated by the example of porous silica materials) or in the laboratory.

Ecological aspects of hydrophobic hydration are manifold. Climate change due to stabilization /destabilization of huge deposits of natural gas in the form of 'soft' hydrate material seem the most important on large time scale whilst geohazards and resource of energy are important also on the short time scale. Common occurrence of hydrophobic hydrates on earth is a firm basis for further research of these complex systems, so important for biological life on our planet.

[1] "Exploring nanoscale hydrophobic hydration, Peter J. Rossky, Faraday Discuss., 2010, 146, 13-18

[2] Water structure and science, Martin Chaplin (Ed) http://www.btinternet.com/ martin.chaplin/phobic.html

3] "The structure of the ionic clathrate hydrate of tetrabutylammoniumvalerate, $\left(\mathrm{C}_{4} \mathrm{H}_{9}\right)_{4} \mathrm{NC}_{4} \mathrm{H}_{9} \mathrm{CO}_{2} \cdot 39.8 \mathrm{H}_{2} 0$ " Rodionova T., KomaroV., Lipkowski J., Kuratieva N New Journal of Chemistry, 34,(2010), 432-438.
MS24-01 Structural relationships between chiral and racemic cocrystals. László Fábián, ${ }^{\mathrm{a}}$ Simon E. Lawrence, ${ }^{\mathrm{b}}$ Anita R. Maguire, ${ }^{\mathrm{c}}$ School of Pharmacy, University of East Anglia, Norwich, United Kingdom, ${ }^{b}$ Department of Chemistry, University College Cork, Cork, Ireland, ${ }^{c}$ Analytical and Biological Chemistry Research Facility, University College Cork, Cork, Ireland

E-mail: 1.fabian@uea.ac.uk

Racemic crystals are expected to be more stable than their chiral counterparts, because racemic space groups provide more possibilities for favourable packing arrangements than chiral ones [1]. Recent results suggest that this overall stability trend also applies for cocrystals [2-5]. Consequently, the relationship between the packing patterns obtained when co-crystallising enantiopure or racemic coformers with the same compound is of particular interest [6-9]. Both our own observations $[2,3,9]$ and a survey of the literature (21 pairs of cocrystals) suggest that cocrystal packing is unusually conservative: chiral/racemic cocrystal pairs often have identical hydrogen-bond networks [2-10], a few pairs are isostructural $[3,6,7,10]$, and some have even been found to form solid solutions [10]. The structures demonstrate that the following factors contribute to the similarity of chiral and racemic cocrystals: (a) A carefully designed hierarchy of strong supramolecular synthons dictates the same relative orientation of the molecules irrespective of their chirality. (b) The hydrogen-bond motifs involved often show a preference towards centrosymmetric arrangements [11]. (c) The steric difference between the enantiomers of popular chiral coformers is often small, e.g., limited to the different orientation of a single methyl group. This allows different enantiomers to occupy the same place in a close-packed array, although usually at the price of some conformational strain. As a consequence of these factors, many chiral cocrystals pack with $Z^{\prime}>1$ and with an approximate inversion symmetry, replicating the typical behaviour of quasiracemates [12].

[1] Brock, C. P., Schweizer, W. B. \& Dunitz, J. D. (1991). J. Am. Chem. Soc., 113, 9811-9820.

[2] Firščić, T., Fábián, L, Burley J. C., Jones W. \& Motherwell, W. D. S. (2006). Chem. Commun., 5009-5011.

[3] Firščí, T., Fábián, L, Burley J. C., Reid, D. G., Duer, M. J. \& Jones, W. (2008). Chem. Commun., 1644-1646.

[4] Kavuru, P., Aboarayes, D., Arora, K. K., Clarke, H. D., Kennedy, A., Marshall, L., Ong, T. T., Perman, J., Pujari, T., Wojtas, L. \& Zaworotko, M. J. (2010). Cryst. Growth Des., 10, 3568-3584.

[5] Braga, D., Greponi, F. \& Lampronti, G. I. (2011). CrystEngComm, 13, 3122-3124.

[6] Lemmerer, A., Báthori, N. B. \& Bourne S. A. (2008). Acta Cryst., B64, 780-790.

[7] Berry, D. J., Seaton, C. C., Clegg, W., Harrington, R. W., Coles, S. J., Horton, P. N., Hursthouse, M. J., Storey, R., Jones, W., Firščić, T. \& Blagden, N. (2008). Cryst. Growth Des., 8, 1697-1712.

[8] Viertelhaus, M., Hilfiker, R., Blatter, F. \& Neuburger, M. (2009). Cryst. Growth Des., 9, 2220-2228.

[9] Eccles, K. S., Deasy, R. E., Fábián, L, Maguire, A. R. \& Lawrence, S. E. (2011). J. Org. Chem., 76, 1159-1162.

[10] Chen, S., Xi, H., Henry, R. F., Marsden, I. \& Zhang, G. G. Z. (2010). CrystEngComm, 12, 1485-1493.

[11] Dey, A. \& Pidcock, E. (2008). CrystEngComm, 10, 1258-1264.

[12] Kelley, S. P., Fábián, L. \& Brock, C. P. (2011). Acta Cryst., B67, 79-93.

Keywords: cocrystals; chirality; hydrogen-bond patterns 